\title{
Enhancement Plan for Overall Disaster Prevention System
}

\author{
Sang-Ho Moon, Member, KIMICS
}

\begin{abstract}
In Korea, overall disaster prevention system or 119 emergency rescue system has been established to protect life and fortune of citizens. This system supports command \& control operation, emergency 119 caller location indicator, automatic formation of fire troops and dispatch, and emergency management. To do this, various new information technologies such as GIS, telematics, CTI and TTS are applied to implement the system. In the future, however, it is not impossible to prevent a large scale disasters caused by world climate environment change and complication of city culture using the current system. In this paper, we propose enhancement plan for overall disaster prevention system to solve this problem.
\end{abstract}

Index Terms-Disaster Prevention System, Fire Fighting Service, Emergency Rescue System

\section{INTRODUCTION}

In modern society, the larger-scale disasters are happened because of increased risks related to usage of energy such as electricity, gas, oil and complication of urban structures. Also, nowadays, various kinds of disasters caused by world climate environment change and complication of city culture are bringing about much loss of life casualties and damages of property. In general, disasters are classified into 8 categories(fire, forest fire, collapse, explosion accidents, traffic accident, pollution, ferry, ocean accidents). These disasters are managed typically through the steps of prevention, preparation, response, recovery[7][8]. According to developing society, also, a desire for the safety of citizens has been rising. Thus, overall disaster prevention system became necessary to cope effectively with these environmental changes and public safety requirements[1][2][3].

The government is making every effort to prevent these kinds of disasters that bring about great social loss[4][5]. A fire-fighting which has a purpose to protect life and property of citizens from various emergency and disaster is an essential organization about disaster

\footnotetext{
Manuscript received January 17, 2011; revised January 29, 2011; accepted February 7, 2011.

Sang-Ho Moon is with the Department of Computer Engineering, Pusan University for Foreign Studies, Busan, Korea (Tel: +82-51-6403584, Fax: +82-51-640-3038, Email: shmoon87@pufs.ac.kr)
}

response. Disaster management based on information systems is one of the most important topics in modern society, and many countries are concentrating on building an emergency management system and infrastructure. In Korea, overall disaster prevention systems or 119 emergency rescue systems have been established since the mid-1990s as a part of the computerization of the fire service which began in Seoul and spread to other regions such as Daegu, Busan, Ulsan, Gwangju and so on. These systems are successfully operated now in regional fire headquarters[1][2][3].

These overall disaster prevention systems have improved conventional fire processing methods which are inefficient because of manual command based on experiences and intuitions of firefighters. Based on vulnerable wire and wireless network, in detail, the systems provide various computing services such as 119 emergency calls and receipts, order to move, situation management and termination. Therefore, it is possible to support scientific and systematic responses on disasters because the systems offer complete computerization services from rapid mobilization order to serving information of disaster fields.

To provide useful computing services, most overall disaster prevention systems utilize latest technologies such as GIS(Geographic Information System), telematics, CTI(Computer Telephony Integration) and TTS(Text to Speech)[4][6][7]. In the future, however, many natural disasters such as tsunami are happened frequently because of an insecure environment and manmade disasters are more large-scaled because of risks related to various energy usage and the complication of urban structures. In the existing overall disaster prevention systems, thus, limits are reached finally to deal with these natural or manmade disasters. In this paper, we look into several enhancement plans to upgrade and improve functions of the overall disaster prevention system for overcoming these limits.

\section{OVERALL DISASTER PREVENTION SYSTEM}

In domestic, overall disaster prevention systems operated now in regional fire headquarters are named differently 119 total information systems or emergency rescue systems according to the feature of projects. Although the system names are rather different, whole 
structures and functions of the systems are almost same[1][2][3][7]. Figure 1 shows the structure of the general overall disaster prevention systems.

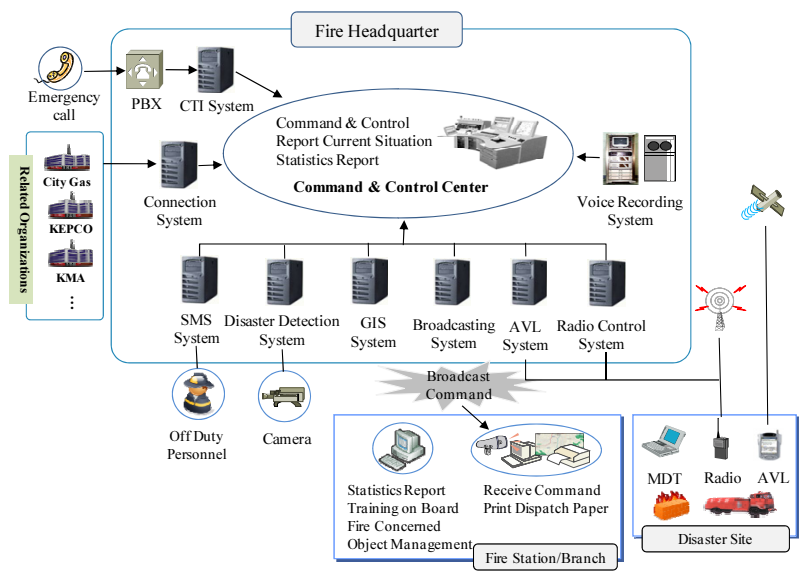

Fig. 1. Entire Configuration of Overall Disaster Prevention System

In general, the system is established to be responsible for the entire emergency rescue operations including main work phases and functions. The system is largely divided into 4 parts such as report \& receipt operation, command $\&$ control operation, disaster on-site information support, and administration information management[6][7]. The system must be operating 24 non-stop services by physically dualization of servers. The information created in the case of disaster is gathered systematically and utilized real-time to control disasters effectively.

In order to understand the basic architecture of overall disaster prevention system, first look into a report system. When citizens take 119 emergency calls, the report system provides exact caller location and information to be possible to rapid mobilization on disaster site. If a flood of emergency calls are occurred in case of largescaled disasters(e.g. typhoon, fire of buildings), the system should distribute calls fairly to the desk by intelligent and automatic ways. Table 1 shows detailed systems and functions related to the report system.

TABLE 1

\section{COMPOSITION OF THE REPORT SYSTEM}

\begin{tabular}{|l|l|}
\hline \multicolumn{1}{|c|}{ Detailed system } & \multicolumn{1}{|c|}{ Function } \\
\hline $\begin{array}{l}\text { CTI call control } \\
\text { system }\end{array}$ & $\begin{array}{l}\text { When 119 emergency calls are } \\
\text { received, distributes intelligently calls } \\
\text { according to status of front desks. }\end{array}$ \\
\hline recording system & $\begin{array}{l}\text { Records voices of calls \& receipts, } \\
\text { communication related to control } \\
\text { disasters, and so on to retrace the } \\
\text { course of disaster processing. }\end{array}$ \\
\hline GIS system & $\begin{array}{l}\text { Displays a caller location and related } \\
\text { spatial and non-spatial information on } \\
\text { electronic maps. }\end{array}$ \\
\hline
\end{tabular}

\begin{tabular}{|l|l|}
\hline ARS/TTS system & $\begin{array}{l}\text { Guides mentions about crank calls, } \\
\text { mistake calls, calls on same disasters } \\
\text { reported already. }\end{array}$ \\
\hline $\begin{array}{l}\text { related } \\
\text { organizations } \\
\text { connection } \\
\text { system }\end{array}$ & $\begin{array}{l}\text { Transfers the information of called } \\
\text { report to related organizations(e.g. city } \\
\text { gas, KEPCO) by system, terminal and } \\
\text { fax. }\end{array}$ \\
\hline $\begin{array}{l}119 \text { mobile phone } \\
\text { location } \\
\text { information } \\
\text { system }\end{array}$ & $\begin{array}{l}\text { Traces the location of a mobile phone } \\
\text { which is 119 emergency called. }\end{array}$ \\
\hline
\end{tabular}

A command \& control system is operated by the fire headquarter office and makes the best use of various kinds of information such as caller location. To swiftly and accurately respond to disasters, the system provides valuable computing services like as issue of notices and mobilization orders on the disaster, automatic formation of fire troops(firefighters, fire engines, and equipments) and dispatch, management of disasters(fire, emergency, rescue and etc.), reporting of current situation. Table 2 shows about detailed systems and functions related to the command \& control system.

TABLE 2

\section{COMPOSITION OF THE COMMAND \& CONTROL} SYSTEM

\begin{tabular}{|l|l|}
\hline Detailed system & \multicolumn{1}{|c|}{ Function } \\
\hline broadcast system & $\begin{array}{l}\text { Broadcasts mobilization orders through } \\
\text { the related fire station/police offices by } \\
\text { network devices after automatic } \\
\text { formation of fire troops and dispatch. }\end{array}$ \\
\hline $\begin{array}{l}\text { vehicle control } \\
\text { system }\end{array}$ & $\begin{array}{l}\text { Provides vehicle real-time location on } \\
\text { the move and all sort of field support } \\
\text { information }\end{array}$ \\
\hline $\begin{array}{l}\text { wireless control } \\
\text { system }\end{array}$ & $\begin{array}{l}\text { Controls wireless communication status } \\
\text { during the use of wireless radio } \\
\text { transmitters in the fire headquarter } \\
\text { office. }\end{array}$ \\
\hline
\end{tabular}

When disasters are occurred, it is important to order to move quickly and acquire more information on the spot preferably for processing disasters efficiently. Disaster on-site information system supports these functions. This system should provide technical skills for accurate disaster control and prevention decision making by various information on the spot. In details, vehicles arrived at the scene of disasters (e.g. fire engines, ambulances) transferred photos and videos taken in the field by cameras embedded in the vehicle. Thus, staffs in fire headquarter put this information to good use for suppressing disasters. Fig. 2 shows the configuration of disaster on-site information system. 


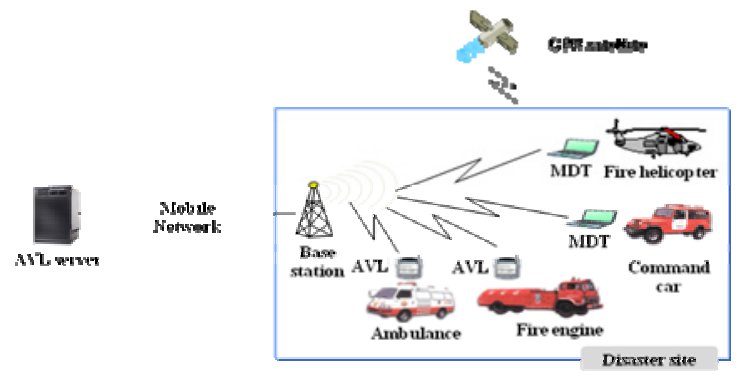

Fig. 2. Disaster on-site information system configuration

Lastly, there is an administration support system for making operation reports related to handling of disasters like as fire, emergency and rescue, and analyzing statistical data about disasters. Also, the system manages major data related to disaster prevention such as fire fighting water, disaster information, fire operation information and so on. Table 3 shows detailed systems and functions of the administration support system.

TABLE 3

COMPOSITION OF THE ADMINISTRATION SUPPORT SYSTEM

\begin{tabular}{|l|l|}
\hline \multicolumn{1}{|c|}{ Detailed system } & \multicolumn{1}{|c|}{ Function } \\
\hline $\begin{array}{l}\text { statistics report } \\
\text { system }\end{array}$ & $\begin{array}{l}\text { Writes operation reports about } \\
\text { activities like as 119 emergency and } \\
\text { analyzes various statistics. }\end{array}$ \\
\hline $\begin{array}{l}\text { fire-fighting } \\
\text { object } \\
\text { management } \\
\text { system }\end{array}$ & $\begin{array}{l}\text { manages fire-fighting objects to } \\
\text { disaster prevention such as fire fighting } \\
\text { water, disaster information, fire } \\
\text { operation information and so on. }\end{array}$ \\
\hline
\end{tabular}

Unlike other information systems, the overall disaster prevention system are very complicated and interworked organically among $\mathrm{H} / \mathrm{W}, \mathrm{N} / \mathrm{W}$ and $\mathrm{S} / \mathrm{W}$. Also, the system must be fault-tolerant system which has to operate 24 hours during 365 days. In the system, therefore, the dualization of $\mathrm{H} / \mathrm{W}$ and $\mathrm{S} / \mathrm{W}$ should be supported to offer non-stop services, and embedded exception handling routines that handle various errors happened in operating $\mathrm{S} / \mathrm{W}[6][7]$.

\section{ENHANCEMENT PLAN FOR OVERALL DISASTER PREVENTION SYSTEM}

Crisises caused by 911 terror, tsunami and etc., are continuously increasing at home and abroad because of world climate environment change and complication of city culture. So, it is more important to reinforce the disaster defense system that should be operated in efficient, scientific, and systematic way. To do this, information technology must be actually vastly underutilized. Up to now, national disaster prevention systems are well operated with latest technologies such as GIS, telematics, CTI, and TTS[1][2][3].

In the future, however, natural disasters are happened frequently because an insecure environment and manmade disasters are more large-scaled according to risks related to various energy usage and the complication of urban structures. In the existing overall disaster prevention system, thus, limits are reached finally to deal with these large scaled natural or manmade disasters.

To cope with large scaled disasters efficiently that will be happen in the future, therefore, the disaster prevention system should be improved and reinforced. To do this, in this paper, we propose enhancement plan for the overall disaster prevention system from an information technology of view which should be applied.

\subsection{Digital Convergence Technology}

Digital convergence refers to the convergence of four industries into one conglomerate, ITTCE (Information Technologies, Telecommunication, Consumer Electronics, and Entertainment). Based on digital technologies and digitized content, it encompasses converged devices (such as smartphones, computers, internet enabled entertainment devices and set top boxes), converged applications(e.g. music download on PC and handheld) and converged networks(IP networks). Thus, this technology provides new, innovative services to consumers and business users.

In existing overall disaster prevention system, converged devices such as AVL(Automatic Vehicle Location) and MDT(Mobile Data Terminal) are planted inside fire engines and ambulances[1][2][3]. These devices may offer disaster on-site information(disaster location and situation) through the vehicle control system. However, it is more uncomfortable to firefighters to use since these devices are installed separately inside vehicles physically.

To solve this problem, thus, it is needed to apply digital convergence technology. In details, information for disaster prevention services such as mobilization order, commend \& control should be provided via integrated devices seamless interworked vehicles. Communication devices such as smartphones and radios should be included converged devices integrated inside vehicles for fire-fighting services.

\subsection{Ubiquitous Technology}

Ubiquity is the technology to make people possible to use computing services whenever, wherever, and whatever they use. In the course of ordinary activities, someone "using" ubiquitous computing engages many computational devices and systems simultaneously, and may not necessarily even be aware that they are doing so. Current methods using the system are more efficient than conventional firefighting methods because firefighters 
may do in a timely and appropriate way using valuable information and useful functions via the system.

However, firemen should be facing various difficulties always because of various risks such as flames, poisonous gas, gas explosion on the spot. It is difficult for staffs in fire headquarter office to control disasters efficiently because they can't see field situations directly.

To resolve this problem, thus, it is needed to apply ubiquitous technology. First, in details, it is needed to to attach $u$-chip(e.g. RFID, sensing device) to firefighters' clothes and helmets and so on. It is possible for staffs in fire headquarter offices to control disasters efficiently using useful field information which is sent in real time by $u$-chip. Also, firefighters may put out the fire effectively since they handle the crisis of field situation rapidly using valuable information(e.g. flame temperature, poisonous gas) sent by $u$-chip in real time.

\subsection{Real-time Image Processing Technology}

For observe city accidents, vulnerable areas, black spots and forest fires, the overall disaster prevention system offers a disaster detection system which can monitor the scenes of disaster in real time with high efficient surveillance cameras. In this system, however, it is a lot of difficulties for directors inside the office to monitor the scene continuously because they should control the direction of the camera on $\mathrm{S} / \mathrm{W}$ manually to observe spots of disasters. Also, the passive operations for setting camera in motion may take a long time. In case of disasters and calamities need to require prompt treatments, therefore, there are many problems for handling crisis rapidly because camera operations manually lead to the late recognition of disaster outbreak.

To solve this problem, first, the system should be able to control the direction of camera automatically and intelligently. Also, the system should be able to process images which are sent from cameras in real time. If finds out disasters and calamities during real time image processing, furthermore, the system must inform critical situations to directors of the command and control center. Although current real-time image processing technology takes a great deal of time, it is possible to achieve magnificent effects if put this technology to practical use in the overall disaster prevention system.

\subsection{Wireless Network and Control Technology}

There are some problems in analog TRS(Trunked Radio System) now in use for communication among firefighters and commanders. It is impossible to keep radio correspondence communication stable(e.g. cause communication problems) in case of getting out of limited areas according to disaster sites or switchboards. Also, this TRS is highly vulnerable to require secure communication and has lower communication quality. Although a wireless network is essential to control the order related with disasters, command \& control and etc. the current analog TRS has lots of constraints in use.

To solve these problems, it is required to construct integrated wireless networks with using a digital TRS like TERRA. The advantage of the digital TRS is that it is the superior quality of voice communication. Also, it is possible to radio correspondence stable on the move and to keep secure communication because prevents tapping of radios. Since offers national coverage widely, added to that, this does much to improve the efficiency of most disaster processing works because of increasing delivering messages and sending multimedia data such as photos and videos. A huge budget, of course, is needed to build the infrastructure for wireless networks. For integration of 119(firefighting), 112(police) and etc., like as VIRVE which is the integrated network of Finland, the national united network should be constructed to handle national disasters efficiently.

\subsection{Robotics Technology}

Robotics is a branch of science and engineering dealing with the study of robots. It is involved with a robot's design, manufacture, application, and structural disposition. Robotics is related to electronics, mechanics, and software. Robot is expected to do lots of things which people can not. For example, recently, fighting robots which can combat in war are invented.

Unfortunately, there are often firemen die on the job from the scene of a fire, because of the suppression of disaster is based upon a premise of the firemen with lifeand-death risk. Furthermore, this unhappiness will be getting serious and spreading in the future in case of large scaled disasters.

The development of the robots which should be suppress disasters suitably might be the best solution to this problem. Therefore, robotics technology becomes more and more important for firefighting services to develop robots that do firefight. If put this technology to practical use, firefighter robots will reduce the sacrifice of firemen in the field. In details, it is possible for firemen to operate the robots with remote controls away from the scene of a fire. Therefore the robots should extinguish a fire automatically without life-risking firemen.

\section{CONCLUSIONS}

In this paper, we examine the overall disaster prevention system briefly for protecting the public's life and wealth from all sort of disaster. This is the most important system among those that must be operated reliably and effectively. Although this system is operating now normally in regional fire headquarters, functional limits of the system are reached finally to deal with large scaled natural or manmade disasters that will be occurred 
in the future because of risks related to various energy usage and the complication of urban structures.

To resolve this problem, we propose some enhancement plans to improve various functions of future overall disaster prevention system technically. In details, it is important to make full use of high state-of-the-art technologies such as digital convergence technology, ubiquitous technology, real-time image processing technology, wireless network and control technology, and robotics technology.

We are hoping that through future study it will eventually be able to apply these technologies in the development of superb system. To achieve this, a specific plan should be set up in the analysis and design phase of system structures.

\section{REFERENCES}

[1] Ulsan Metropolitan Fire Headquarter, Total Disaster Prevention System Building Project Workshop, 2005.

[2] Busan Metropolitan Fire Headquarter, 119 Total Information System User and Operator Guide Manual, 2002.

[3] Daegu Metropolitan Fire Headquarter, Design Documentations of 119 Emergency Rescue System, 2004.

[4] I.-B. Kim, S.-H. Kim, H.-S. Park, I-DW System for Effective Decision Making of Fire Prevention, Int'l Fire and Safety EXPO Spring Conference, 2005.

[5] Ministry of Government Administration and Affairs, An Annual Report of Disasters in 2003, 2004.

[6] D.-Y. Kim, S.-H. Moon, Development of an AVL System for Fire Fighting Services, Journal of KIMICS, Vol. 14, No. 4, pp.886-892, 2010.

[7] D.-S. Baek, Fire Emergency Response System Based on GIS Daegu Metropolitan City FGIS, Journal of KAGIS, Vol. 7, No. 4, pp.109-118, 2004.

[8] KRIHS, Emergency and Disaster Response with GIS, Proceeding of $9^{\text {th }}$ Int'l Seminar on GIS, 2004.

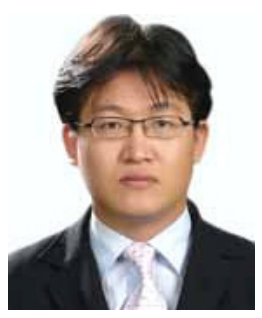

Sang-Ho Moon received the B.S. and M.S degrees in computer engineering from Busan National University, South Korea. He received $\mathrm{Ph} . \mathrm{D}$ degree in 1998 at the computer engineering of Busan National University, South Korea. $\mathrm{He}$ is currently with the Department of Computer Engineering, Pusan University of Foreign Studies as an Associate Professor. His research interests are Database Systems, Geographic Information Systems/ Spatial Databases, Information System Audit. 